\title{
Determining Digital Transformation Success Factors
}

\author{
Resego Morakanyane \\ University College Cork \\ resego.morakanyane@gmail.com
}

\author{
Philip O'Reilly \\ University College Cork \\ philip.oreilly@ucc.ie
}

\author{
John McAvoy \\ University College Cork \\ j.mcavoy@ucc.ie
}

\begin{abstract}
To understand what organizations do which brings about successful digital transformation $(D X)$, a review of representative literature was performed. From a total of 89 articles, 16 single-case articles which sufficiently documented end-to-end DX success stories of 10 exemplar organizations were selected. Within case content analysis and asking the questions analytical procedure were employed to code each exemplar case, where a total of 174 attributes were found. Making the comparisons procedure was employed to build thematic higher-level categories by grouping similar attributes. Cross case content analysis was employed to determine presence strength of attributes in the category groupings. A list of 7 success factors and 23 subfactors emerged from the thematic groupings. These success factors constitute the initial steps towards building a DX framework which organizations seeking to embark on successful digital transformation journeys can adopt.
\end{abstract}

\section{Introduction}

Digital transformation (DX) is an evolutionary process that leverages digital technologies and capabilities to enable business models, operational processes and customer experiences to create value [5]. In this process, rapid development and adoption of emerging digital technologies commonly known as SMAC change the business competition landscape by invading organizations and redrawing operating rules $[38,39]$ as well as inventing new customer relationships, operations and business models [40, 41, 42]. This compels organizations to leverage these technologies to keep up with changing competitive playing field $[1,19,43,44,45]$ and evolving requirements of today's digital savvy customer $[8,11$, 16]. [11] argues that digital transformation affects all organizations across all industries, warning organizations that wish to remain relevant in their market sectors to leverage the digital opportunities and transform.

However, an MITSloan and Deloitte study reveals that digital transformation proves to be difficult and less understood by many organizations [46]. The study illustrates that digitally maturing businesses focus on integrating digital technologies in transforming their businesses whereas less mature ones focus on solving discrete problems with individual technologies. Further research reveals that while many organizations continue to embark on DX, only one in five organizations are succeeding in realizing the true value of transformation $[1,2,3]$. This uncertainty sparks new research interest where academics wish to understand "what organizations succeeding in DX (herein referred to as digital exemplars) are doing, which enables them succeed" as well as "how they do what they do to succeed in their journeys" while practitioners are looking at "development of tools that will guide them to achieve successful digital transformation". To understand this, we carried out a qualitative analysis of 16 DX case study articles to draw from them attributes that imply DX success. Our analysis revealed a total of 7 success factors, 23 subfactors and attributes. These factors contribute as initial steps towards building success framework which organizations seeking to embark on digital transformation journeys can adopt.

This paper therefore seeks to address the questions: "What do digital exemplars do that enables them to succeed in their digital journeys, as well as how they do it." In the next section we give a brief analysis of the DX literature and contextualize our approach to DX success factors. We then illustrate the eight steps of data collection and coding used in this study and explain the analysis process followed. Next we present and discuss the findings, illustrating these through open coding process examples. We conclude the paper by presenting the proposed $7 \mathrm{DX}$ success factors as a foundation toward building DX Success Framework and share next steps of empirically validating the factors. The paper contributes to the body of knowledge of successful digital transformation as well as a guideline to give managers a starting point towards successful DX. 


\section{Literature review}

There is ongoing research seeking to contribute towards digital transformation body of knowledge. Major works include literature reviews aiming at: conceptualizing the phenomenon $[4,5,35,36,48]$; understanding DX strategies [11, 20, 21, 46, 49, 50, 51, 53]; leadership [27, 33, 54, 55, 56] as well as the future of $D X[38,44,57,58]$. There is also a growing interest of how DX has revolutionized different industries [20, $37,59,60,61,62,63]$. At organizational level, there is research sharing experiences, impacts, challenges and lessons learnt during $D X$ journeys of such organizations $[7,9,11,14,16,22,23,24,27]$. Also, there is studies sharing transformation experiences at functional and operational levels of organizations [8, $18,32,64]$.

Despite the growing research interest in different aspects of DX, researchers still note a lack of understanding of $D X$ as a phenomenon, including limited development of tools to help managers when embarking on DX journeys (frameworks and guidelines), insufficient business cases to justify the need to embark [43]; with also limited scientific research that theoretically explains its concepts $[4,48$, 63]. Few articles that discuss factors and attributes that enhance successful DX include [49] who developed a DX framework with technology, changes in value creation, structural and financial as the four dimensions for guiding formulation of DX strategy. Further, [4] investigated drivers and objectives, success factors and implications of digital transformation while [65] discovered 8 dimensions and 26 characteristics of a DX success framework through empirical validation.

[65] goes on to emphasize importance of advancing research on DX success as an emerging issue to complement existing IS success research by $[66,67$, 68]. DX is a complex, expensive and volatile endeavor in which organizations take risks in pursuit of major long term efficiency and productivity gains [42, 49, 69]. Getting DX journeys correct is therefore of high importance. Organizations seeking to embark successfully therefore need to know why they want to transform, what aspects of their businesses they want to transform, technologies to leverage as well as desired results from these transformations. In light of these, we found it fitting to focus our study on learning from digital exemplars what they did to succeed in their DX journeys and how they did it. We do this by examining journeys of digital exemplars, extracting factors and attributes that suggest successful digital transformation. To put to context what success factors and attributes are and how to identify them, we drew from [29]'s description of success factors who describe them as: 1) factors linked to success by a known causal mechanism; 2) factors necessary and sufficient for success; 3) factors necessary for success; and 4) factors associated with success. The following section explain how we searched for appropriate digital exemplar case studies and analyzed them using content analysis to discover the list of DX success factors.

\section{Research design}

Our data collection, coding and analysis process draws from the eight steps of data collection and coding adopted from $[28,30]$, with an edition of one step identification of relevant literature [70]. Below we illustrate how these steps were used:

\section{Step 1: Identification of relevant literature}

In this step, we describe the process followed to search and select articles eligible for analysis. We began our search by browsing through grey literature, drawing from [71] who argue that grey literature is important in complementing systematic literature especially in less published, highly volatile topics. This literature was identified by browsing through different media sources that write on issues of digital transformation extensively. By paying more attention to articles that discuss topics in success of digital transformation, the exercise gave us hint on keywords to develop as well as how to look for success attributes. Search criteria for scholarly articles was developed. The criteria entailed searching through leading journals and conferences on scholarly databases such as SCOUPUS, Science Direct, EBSCO and Emerald Insight. Due to insufficient scholarly articles documenting DX journeys and success stories of organizations, relevant articles from other credible sources such as consultancy reports were also considered. Search keywords used include: digital transformation success factors, successful $D X, D X$ success stories, DX lessons learnt, DX success attributes, business digital strategy success. The search targeted articles written in English and published after 2010 , the period that saw rise in use and adoption of digital technologies. 89 articles were initially obtained from this search. Further interrogation of the articles revealed 67 articles of non-empirical contribution and 22 articles with single case study empirical contribution [4]. Since our aim was to learn from organizations with successful DX stories, only 22 articles were considered for possible further analysis. We then decided to consider only articles with a comprehensive level of detail of the digital exemplar's journey. Table 1 below presents a summary of the search process and articles identified. 


\begin{tabular}{|c|c|}
\hline Type of Publication & No. of Articles \\
\hline $\begin{array}{c}\text { Non-empirical } \quad \& \quad \text { multi } \\
\text { case studies }\end{array}$ & 67 \\
\hline Non-exemplar single case studies & 6 \\
\hline Exemplar single case studies & 16 \\
\hline Total & 89 \\
\hline
\end{tabular}

"Table 1. Summary of articles obtained during data collection"

16 articles were then selected for the final analysis. The articles (referred to as exemplar cases) gave an end-to-end, in-depth account of DX journeys of 10 digital exemplars. Details of these articles are illustrated in table 2 in section 4.

\section{Step 2: Decide the level of analysis}

In this step researchers decide what the level of analysis should be [28, 30]. This could be a signal word, a set of words, phrases or the entire document. In this study, we chose level of analysis to be the entire document. It was therefore vital that articles being selected for analysis were of appropriate content, relevance and depth to reveal DX success factors. As such, the 16 articles mentioned above were analyzed in their entirety using open coding techniques.

\section{Step 3: Decide how many concepts to code for}

In this step, researchers decide whether to code text using a predefined set of concepts or develop a list of concepts incrementally during the coding process [28, 30]. In this study concepts were developed incrementally during the coding process. An NVivo file was created to capture attributes emerging during the coding process.

\section{Step 4: Decide whether to code for the existence or frequency of a concept}

In this step, researchers decide whether to code for the existence or frequency of concepts $[28,30]$. In this study we coded for existence of concepts. However, as frequency of the concepts recurred with the coding of the cases, frequency of codes was then considered in order to gain a deeper insight of the concepts [30].

\section{Step 5: Decide on how you will distinguish between the concepts}

In this step, researchers decide whether to code the concepts exactly as they appear, or if they can be coded in some altered or collapsed form [28, 30]. In our study, all concepts that carried similar meaning but written differently were placed within the same category and coded together. Figures 1 and 2 in section 5 illustrate how this step was applied, where concepts that carried similar meaning but written differently were coded together.

\section{Step 6: Develop rules for coding your text}

In this step, researchers develop translation rules that ensure consistency of the coding procedure [28, 30]. The following rules were developed and applied during the coding process:

- Articles of each exemplar case were loaded on the

- NVivo file and read line by line

- Using content analysis, excerpts containing concepts that suggest DX success were highlighted from the article

- Corresponding attributes (nodes) were created to capture concepts as they emerged from the excerpts and the excerpts were mapped to the corresponding attribute (node) on the list

- Each attribute listed had an imperative verb denoting action taken or occurred event

- Attributes were examined to identify similarities and differences in order to develop themes and subthemes

- Articles were then re-read to determine if all concepts/attributes had been captured and verify if each concept was coded under the appropriate node

- Each attribute was thoroughly examined to determine if it could be subdivided further into subnodes or joined with other nodes to make a higher level node

- Attributes with overall low frequency in the analysed literature were then discarded

\section{Step 7: Decide what to do with 'irrelevant' information}

In this step, researchers decide what to do with information that was not coded [28, 30]. While an entire paper was analysed, only concepts that describe activities carried out during the DX journey as well as the transformation process followed were considered. Any information outside this description was considered irrelevant and was discarded.

\section{Step 8: Coding the text}

In this step, researchers carry out the actual coding process [28, 30]. To execute coding, a set of predetermined questions were developed to guide the process. Open coding techniques were adopted, where "asking the questions" analytic procedure was used to carry out within case and cross case content analysis of the articles; and "making of the comparisons" analytical procedure was applied to categorize attributes with similarities into thematic factors. In 
asking questions procedure, we analyzed emerging concepts extracted from the main text to establish what attributes they describe. We then coded the concepts under appropriate attributes. The process required careful line-by-line examination of the text. Making of comparisons procedure entailed comparing attributes with each other for similarities and differences. Attributes found to be conceptually similar were grouped together under a higher-level descriptive category $[31,32]$. Translation rules identified in step 6 were followed and the process was repeated to ensure that all concepts were captured and that relevant categories were created to represent DX success factors, subfactors and underlying attributes.

\section{Step 9: Analysing the results}

In this step, researchers decide how to review and present the results $[28,30]$. In this study, a list of success attributes later categorized into themes of success factors, denoting what exemplars did and how they succeeded in their digital transformation journeys, was created. Our findings therefore present the list of success factors and subfactors obtained from this analysis, as well as demonstrate how the factors emerged. Section below describes the analysis process followed in this study.

\section{Analysis}

Identification of relevant literature stage retrieved an initial list of 89 articles as relevant for potential analysis. Upon browsing through these articles iteratively, 16 articles were subsequently selected for final in-depth analysis as exemplar cases. The 16 articles had sufficiently documented end-to-end DX success stories of 10 digital exemplar organizations. Also, the articles had met [57]'s requirement of a digitally transforming organization. Table 2 below presents the 16 case studies in 10 exemplar cases. This is because some of the exemplar cases were documented in more than one article. In this instance, articles of the same digital exemplar were used for data triangulation during analysis.

\begin{tabular}{|l|l|}
\hline Exemplar Case & Article \\
\hline Burberry - Retail & $\begin{array}{l}\text { HBR [6]; CapGemini Consulting } \\
\text { [7]; J. of Fashion Mrktg \& Mgmt [8] }\end{array}$ \\
\hline Hummel - Retail & MIS QE [9] PhD \\
\hline Starbucks - Retail & $\begin{array}{l}\text { J. of Knwl. Mgmt [10]; MITSloan } \\
\text { Review [11]; MISQE [12]; } \\
\text { CapGemini Consulting [13] }\end{array}$ \\
\hline Retail Co - Retail & MISQE [14] \\
\hline L'Oreal - Retail & CapGemini Consulting [15] \\
\hline
\end{tabular}

\begin{tabular}{|l|l|}
\hline $\begin{array}{l}\text { DSB Bank - } \\
\text { Banking }\end{array}$ & MISQE [16] \\
\hline $\begin{array}{l}\text { Lloyds Bank - } \\
\text { Banking }\end{array}$ & Forrester Consulting [17] \\
\hline $\begin{array}{l}\text { Audi - } \\
\text { Manufacturing }\end{array}$ & MISQE [22]; MISQE [23] \\
\hline $\begin{array}{l}\text { Lego - } \\
\text { Manufacturing }\end{array}$ & MISQE [24] \\
\hline HAAB - Health & INSEAD [25] \\
\hline
\end{tabular}

"Table 2. DX exemplar case studies"

The 16 articles were loaded on NVivo 11 software and analysed individually. Asking the questions procedure, guided by some probing questions, was employed to extract excerpts from the main text and code them on NVivo software - section 5 below. These probing questions were developed from the main research questions of "what do organizations do to succeed in their DX journeys" and "how do they do that". Examples of these questions include: what did the organization do to begin its DX journey; what characteristic and behavioural traits did the organization exhibit that is associated with enhancing success of the digital journey; how did the organization map out its journey; what tools and techniques did the organization employ; how was the digital agenda coordinated, and at what level, etc. Each line of the main text read was examined to see if it answers any of these probing questions. Statements found to be answering the questions were extracted as excerpts and coded following the procedure described in step 6 above. The questions were used as guideline with openness to allow us to generate new questions as the analysis process matured. It was also imperative that excerpts extracted from the main text focused on answering the main research questions.

When the list of codes in the NVivo software was reasonably exhaustive, the emergent codes were interrogated with making of comparisons procedure. Here, the codes were compared with each other. Conceptually similar codes were grouped together under one higher category while more composite codes were broken down further. In this process, we borrowed from the drifting method [47]. This process enabled us to drift between coding data using asking questions and building categories through making comparisons, as such enabling us to continuously learn from the findings, also removing researchers' bias [52]. Results obtained from this analysis are presented and discussed in the section below. 


\section{Findings and discussions}

Figure 1 and 2 below illustrate how excerpts harvested from the main text were used to discover concepts emerging which were then coded as attributes. In figure 1 for instance, from the first probing question "what do organizations do to succeed in their DX journeys," Lego case emphasized how “...lack of clarity often results in piecemeal initiatives, missed opportunities and false starts in the digitalization of the enterprise..." [24] pp. 141. This statement emphasizes that organizations seeking to succeed in their DX journeys should be clear with what they want to transform; and what they want to transform should be informed by what initiated the journey. For example, in DBS Bank, the need to leverage digital technology was driven by "demands of a growing number of digitally savvy customers..." pp. 107 and “...recognizing that

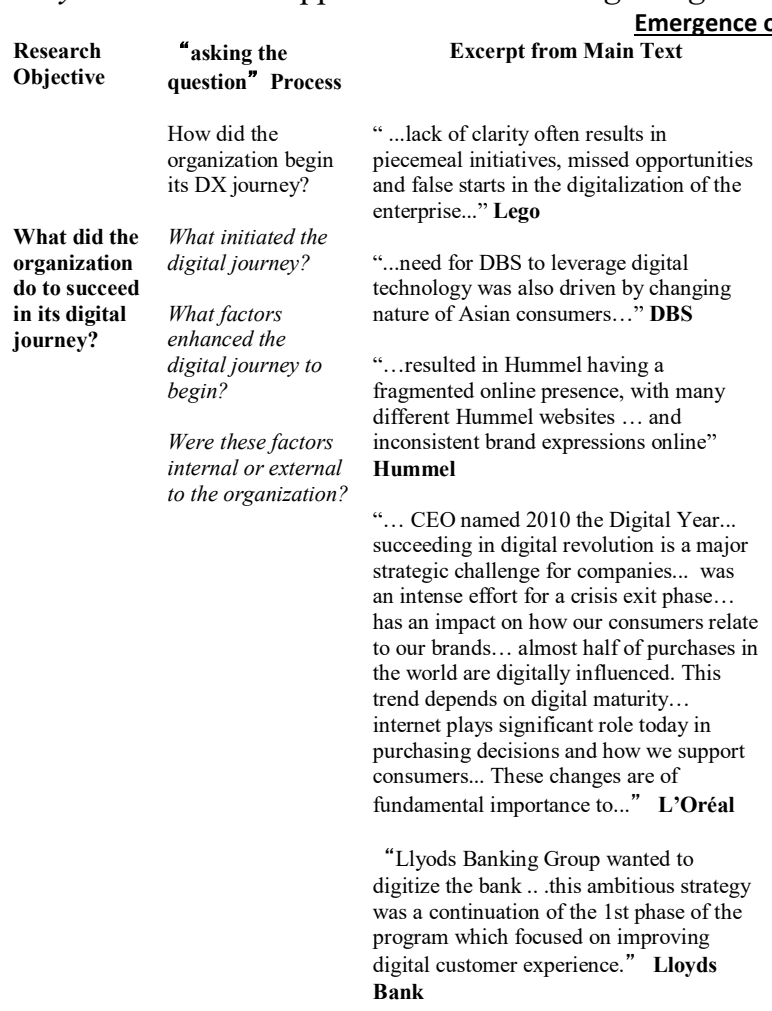

"Figure 1. Emergence of Digital Trigger"

In the same manner, by asking "what characteristic and behavioral traits did the organization exhibit which are associated with a succeeding digital journey" RetailCo team "embraced a flexible approach whenever possible to pursue an effective, pragmatic the banking industry was undergoing cataclysmic disruption, the CEO personally championed the digital agenda, putting digital at the heart of banking" [16] pp. 108. From these excerpts, concepts such as changing needs and behavior of customers emerge. These "changing needs and behaviors of customers" arguably are what induced the bank's digital journey, hence we say the digital journey of DBS Bank was TRIGGERRED by customer-induced factors, and that this was taking place in the external environment of the bank. We therefore propose that in order to be clear with what they want to transform, organizations must first know what factors trigger the need to embark on a DX journey. That is, they must know what internal and external attributes induced their need to transform.

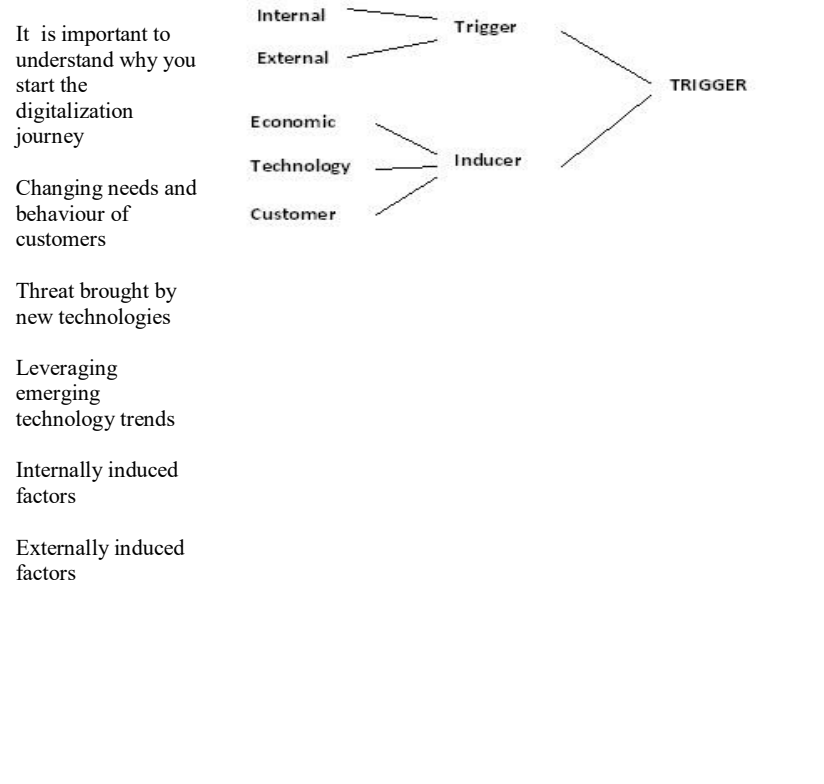

path to the desired objectives" [14]. By embracing flexible approach, RetailCo is exhibiting strong leadership traits which are required to cultivate a digital culture [18]. Figure 2 below illustrates how the digital organization success factor emerged. 


\begin{tabular}{|c|c|c|c|}
\hline $\begin{array}{l}\text { Research } \\
\text { Question }\end{array}$ & $\begin{array}{l}\text { “asking the } \\
\text { question" process }\end{array}$ & Excerpt from Main Text & 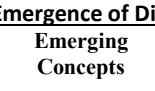 \\
\hline $\begin{array}{l}\text { How did } \\
\text { it do that? }\end{array}$ & $\begin{array}{l}\text { How was the DX } \\
\text { effort coordinated } \\
\text { across the } \\
\text { organization } \\
\text { At what level was } \\
\text { the digital effort } \\
\text { coordinated? } \\
\text { Who led the digital } \\
\text { mandate? } \\
\text { How was digital } \\
\text { mandate } \\
\text { implemented at } \\
\text { functional and } \\
\text { operational level? }\end{array}$ & $\begin{array}{l}\text { “...form a new Group } \\
\text { Technology and Operations } \\
\text { (T\&O) Division under Mr. } \\
\text { Gledhill as Head ...” DBS } \\
\text { “...on the front end we hired a } \\
\text { young dynamic team which } \\
\text { resembled our customers and } \\
\text { on the back end we installed } \\
\text { infrastructure to support this } \\
\text { effort” Burberry } \\
\text { “...created Starbucks Digital } \\
\text { Ventures: an internal, venture } \\
\text { capital-style incubator for } \\
\text { digital technology. The unit } \\
\text { remained separate from the } \\
\text { company's Marketing and IT } \\
\text { groups, but collaborated } \\
\text { closely with both to drive } \\
\text { innovation in the company's } \\
\text { digital strategy...” } \\
\text { Starbucks } \\
\text { “...created AUDI Business } \\
\text { Innovation... its role is to } \\
\text { extend capabilities of existing } \\
\text { departments... to develop and } \\
\text { implement digital business } \\
\text { innovations.” Audi }\end{array}$ & $\begin{array}{l}\text { Appoint } \\
\text { Digital Head } \\
\text { Establish } \\
\text { stand-alone } \\
\text { digital } \\
\text { functional unit } \\
\text { Establish } \\
\text { digital } \\
\text { functional } \\
\text { structure } \\
\text { Collaboration } \\
\text { with other } \\
\text { units across } \\
\text { the } \\
\text { organization }\end{array}$ \\
\hline
\end{tabular}

"Figure 2. Emergence of Digital Organization"

Following asking the questions procedure described above, 174 attributes were discovered from NVivo coding. Two new levels of higher categories emerged from making of comparisons procedure. The levels were used to categorize related attributes into themes (success factors) and subthemes (subfactors) where 7 themes and 23 subthemes emerged. The iterative process of building these three category levels entailed continuously revising the list of attributes, subfactors and factors through the drifting process. To reduce authors' bias, the list was discussed with independent DX experts who have great insight on DX success issues, as well as with other researchers who shared the same interest of developing DX success factors [34].

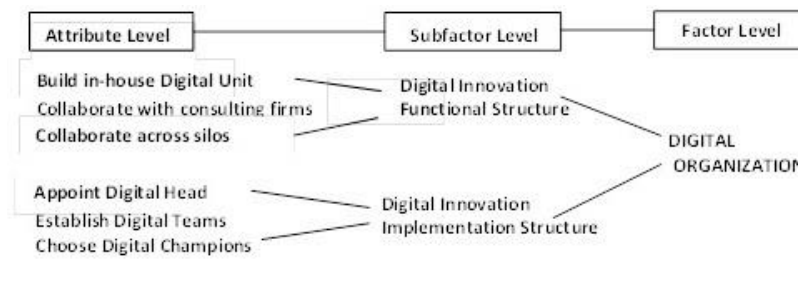

This process was repeated with all 16 articles of the 10 exemplar cases. Themes were built from the emerging attributes to create the 7 success factors. These factors respond to the first research question of what organizations must do to achieve successful digital transformation. The emerging factors carry imperative verbs that describe actions to be taken. The second question is answered by the 23 subfactors which describe how actions in the main factors should be implemented. The underlying attributes then give, at the lowest level of analysis, different variables that enable implementation of actions in the factors and subfactors. Table 3 below presents the final emergent DX success factors and subfactors. The number of underlying attributes is enclosed in the brackets.

\begin{tabular}{|l|l|}
\hline Success Factor (7) & Sub-factors (23) \\
\hline Determine Digital Trigger & Know the type of trigger (2) \\
$(16)$ & Know the type of inducer (14) \\
\hline Cultivate Digital Culture & Ensure a shared conceptualization of DX (7) \\
$(28)$ & Exhibit strong organizational leadership traits (10) \\
& Adopt good governance practices (11) \\
\hline Develop Digital Vision & Carry out a digital present assessment (3) \\
$(16)$ & Formulate a digital future (5) \\
& Develop a digital strategy (2) \\
& Establish a communications strategy (6) \\
\hline Determine Digital Drivers & Determine digital technologies to leverage (12) \\
$(50)$ & Determine skills \& capabilities required (5) \\
& Determine other resources required (3) \\
& Exhibit strong digital leadership traits (30) \\
\hline Establish Digital Organization & Establish a digital innovation functional structure (12) \\
$(15)$ & Create a digital innovation implementation structure (3) \\
\hline
\end{tabular}




\begin{tabular}{|l|l|}
\hline $\begin{array}{l}\text { Determine Transformed Areas } \\
(11)\end{array}$ & $\begin{array}{l}\text { Determine transformation opportunities (4) } \\
\text { Identify target transforming areas (4) } \\
\text { Building the DX initiatives (3) }\end{array}$ \\
\hline $\begin{array}{l}\text { Determine Impacts } \\
(38)\end{array}$ & $\begin{array}{l}\text { Define the expected customer facing impacts (4) } \\
\text { Determine the realized customer facing impacts (9) }\end{array}$ \\
& Define the expected organization facing impacts (4) \\
& Determine the realized organization facing impacts (17) \\
& Determine measures of impacts (4) \\
\hline
\end{tabular}

"Table 3. DX success factors, sub-factors and attributes". $\left({ }^{*}\right)$ no. of attributes

While coding of the 10 digital exemplar cases generally agreed to most of the 174 attributes, it was evident that presence strength of the attributes and factors varied across exemplar cases. To understand these variations, cross case analysis process described in section 3 above was applied. Table 4 below illustrates results from the cross-case analysis, indicating presence strength of attributes in each sub factor.

\begin{tabular}{|c|c|c|c|c|c|}
\hline & \multirow[b]{2}{*}{ FACTORS } & \multirow{2}{*}{$\begin{array}{c}\text { No. of } \\
\text { Attributes }\end{array}$} & \multicolumn{3}{|c|}{ Presence Strength } \\
\hline & & & $\mathbf{W}$ & $\mathbf{M}$ & $\mathbf{S}$ \\
\hline 1 & DETERMINE DIGITAL TRIGGER & 16 & 6 & 3 & 7 \\
\hline 1.1 & Know the type of Triggers & 2 & 0 & 0 & 2 \\
\hline 1.2 & Know the type of Inducers & 14 & 6 & 3 & 5 \\
\hline 2 & CULTIVATE DIGITAL CULTURE & 28 & 5 & 4 & 19 \\
\hline 2.1 & Ensure Shared Conceptualization of Digital Transformation & 7 & 0 & 1 & 6 \\
\hline 2.2 & Exhibit Strong Organizational Leadership Traits & 10 & 1 & 1 & 8 \\
\hline 2.3 & Adopt Good Governance Practices & 11 & 4 & 2 & 5 \\
\hline 3 & DEVELOP DIGITAL VISION & 16 & 0 & 4 & 12 \\
\hline 3.1 & Carry out Digital Present Awareness & 3 & 0 & 2 & 1 \\
\hline 3.2 & Formulate Digital Future & 5 & 0 & 1 & 4 \\
\hline 3.3 & Develop Digital Strategy & 2 & 0 & 0 & 2 \\
\hline 3.4 & Establish a Digital Communication Strategy & 6 & 0 & 1 & 5 \\
\hline 4 & DETERMINE DIGITAL DRIVERS & 50 & 9 & 5 & 36 \\
\hline 4.1 & Determine Digital Technologies to Leverage & 12 & 4 & 0 & 8 \\
\hline 4.2 & Determine Skill \& Capabilities Required & 5 & 0 & 0 & 5 \\
\hline 4.3 & Determine Other Resources Impacting Required & 3 & 1 & 1 & 1 \\
\hline 4.4 & Exhibit Strong Digital Leadership Traits & 30 & 4 & 4 & 22 \\
\hline 5 & ESTABLISH DIGITAL ORGANIZATION & 15 & 4 & 3 & 8 \\
\hline 5.1 & Establish Digital Innovation Functional Structure & 12 & 4 & 3 & 5 \\
\hline 5.2 & Create Digital Innovation Implementation Structure & 3 & 0 & 0 & 3 \\
\hline 6 & DETERMINE TRANSFORMED AREAS & 11 & 0 & 1 & 10 \\
\hline 6.1 & Determine Transformation Opportunities & 4 & 0 & 0 & 4 \\
\hline 6.2 & Identify Target Transforming Areas & 4 & 0 & 0 & 4 \\
\hline 6.3 & Building DX Initiatives & 3 & 0 & 1 & 2 \\
\hline 7 & DETERMINE IMPACTS & 38 & 1 & 5 & 32 \\
\hline 7.1 & Define Expected Customer Facing Impacts & 4 & 0 & 1 & 3 \\
\hline 7.2 & Determine Realized Customer Facing Impacts & 9 & 0 & 1 & 8 \\
\hline 7.3 & Define Expected Organizational Facing Impacts & 4 & 0 & 1 & 3 \\
\hline 7.4 & Determine Realized Organization Facing Impacts & 17 & 1 & 2 & 14 \\
\hline 7.5 & Determine Measure Of Impacts & 4 & 0 & 0 & 4 \\
\hline
\end{tabular}

"Table 4. Attributes presence strength in DX success factors" Attribute Presence Strength: Weak (W), Moderate (M), Strong (S)

The presence of most attributes is strong although frequencies are however sparsely distributed. This is to say, certain attributes and factors emerged more frequently from exemplar cases while some less frequently. For example, 50 attributes were discovered in 'determining digital drivers'. 30 of those attributes 
described 'exhibiting strong digital leadership traits', 12 described 'digital technologies to leverage', 5 described 'skills and capabilities required' and 3 described 'other resources' required to drive DX. Of the 30 'exhibiting strong digital leadership traits' attributes, 22 were frequently present in exemplar cases, 4 moderately present, 4 were weak. This finding sparks an interesting twist to the study where it may be important to investigate: why some attributes and factors emerged more frequently than others; what the frequency of an attribute or factor mean to successful DX; what the frequency imply about the strength and level of influence of the attribute or factor.

\section{Conclusions and further research}

To understand what organizations do which enables them to succeed in their digital journeys, 10 exemplar case studies discussed in 16 articles were selected from a pool of 89 articles. Within case contents of the 16 articles were coded on NVivo software using asking the questions analytical procedure. Emerging attributes were then grouped into thematic categories using making of comparisons analytical procedure, where 7 main categories (factors) and 23 subcategories (subfactors) emerged. Cross case analysis was carried out to determine presence strength of each attribute across the cases. A summary table of presence strengths is presented. Analysis of this table reveals how the presence of attributes is sparsely distributed in each case, making it premature to conclude which factors are more influential to DX success than others.

However, while it is early to reach a conclusion on DX success factors in this study, as next steps we propose establishment of relationships between the factors, an empirical qualitative validation of the emergent list. We also argue that the list can be adopted as building block towards construction of DX success framework. Utility of the list can also be refined and adopted in Design Science Research and Action Design Research Methods towards building Successful DX Framework artefacts. Experienced digital transformation practitioners can also be engaged to validate this emergent success factor list through Emerging Consensus Technique focus groups.

\section{References}

[1] HBR Analytics Services, "The Digital Transformation of Business", Harv. Bus. Rev., 2015.

[2] HBR Analytics Services, "Accelerating the Pace of Digital Transformation", Harv. Bus. Rev., 2016.
[3] G. C. Kane, D. Palmer, A. N. Phillips, D. Kiron and N. Buckley, "Achieving Digital Maturity", MITSloan Manage. Rev. \& Deloitte Univ. Press, 2017.

[4] K. Osmundsen, J. Iden and B. Bygstad, "Digital Transformation: Drivers, Success Factors and Implications", in Proc. of MCIS. 2018.

[5] R. Morakanyane, A. Grace and P. O'Reilly, "Conceptualizing Digital Transformation in Business Organizations: A Systematic Review of Literature", in Proc. of BLED 2017.

[6] A. Ahrendts "Burberry's CEO on Turning an Aging British Icon into a Global Luxury Brand", Harv. Bus. Rev., 2013.

[7] D. Bonnet, "An Interview with Angela Ahrendts - CEO of Burberry: Burberry's Digital Transformation", Digital Leadership, CapGemini Consulting, 2012.

[8] K. Straker and C. Wrigley, "Emotionally Engaging Customers in the Digital Age: the Case Study of Burberry Love", J. of Fashion Mrktg \& Manage., 20(3), 2016, pp. 267-299.

[9] R. Hansen and S. K. Sia, "Hummel's Digital Transformation Strategy Towards Omnichannel Retailing: Key Lessons Learned", MISQE 14(2), 2015, pp. 5166.

[10] A. Y. K. Chua and S. Banerjee, "Customer Knowledge Management via Social Media: the Case of Starbucks," J. of Knwldg. Manage. 17(2), 2013, pp. 237-249.

[11] M. Fitzgerald, "How Starbucks Has Gone Digital”, MITSloan Manage. Rev., 2013.

[12] J. Gallaugher and S. Ransbotham, "Social Media and Customer Dialog Management at Starbucks", MISQE 4(9), 2010, pp. 197-212.

[13] M. Welch and J. Buvat, "Starbucks: Taking the Starbucks Experience Digital", Capgemini Consulting, 2013.

[14] T. Tamm, P. B. Seddon, G. Shanks, P. Reynolds and K. M. Frampton, "How Australian Retailer Enabled Business Transformation Through Enterprise Architecture", MISQE, 14(4), 2015, pp. 181-193.

[15] M. Menesguen, "Beauty and Digital: A Magical Match", Dig. Trans. Rev., CapGemini, 2011, pp. 6-13.

[16] S. K. Sia, C. Soh and P. Weill, "How DBS Bank Pursued a Digital Business Strategy", MISQE, 15(2), 2016, pp. 105-121.

[17] O. Berdak and J. van der Brink-Quintannilha, "Lloyds Banking Group Transforms Through 10 Customer Journeys", Forr. Research, 2017.

[18] D. Liu, S. Chen and T. Chou, "Resource fit in Digital Transformation", Manage. Decision, 49(10), 2011, pp. 1728-1742. 
[19] P. Setia, V. Venkatesh and S. Joglekar, "Leveraging Digital Technologies: How Information Quality Leads to Localized Capabilities and Customer Service Performance", MISQ 37(2), 2013, pp. 565-590.

[20] S. Chanias, "Mastering Digital Transformation: The Path of a Financial Services Provider Towards a Digital Transformation Strategy", In Proc. of ECIS 2017.

[21] S. Chanias, M. D. Myers and T. Hess, "Digital Transformation Strategy Making in Pre-Digital Organizations: The Case of a Financial Services Provider", J. Str. Info. Sys. 28(1). 2019, 17-33.

[22] C. Dremel, M. Herterich, J. Wulf, J. C. Waizmann, and W. Brenner, "How AUDI AG Established Big Data Analytics in Its Digital Transformation," MISQE 16(2), 2017, pp. 81100.

[23] M. Mocker \& N. O. Fonstad, "How AUDI AG is Driving Toward the Sharing Economy", MISQE 16(4), 2017, pp. 279-293.

[24] O. A. El Sawy, H. Amsinck, P. Kræmmergaard and A. L. Vinther, "How LEGO Built the Foundations and Enterprise Capabilities for Digital Leadership", MISQ Executive, 15(2), 2016, pp. 141-166.

[25] S. Mahroum, N. Ferchachi and A. Gomes, "UAE - Health Authority Abu Dhabi", Inside the Black Box: Journey Mapping Digital Innovation in Government, INSEAD, 2018, pp. 36-46.

[26] M. Mihailescu, D. Mihailescu and U. Schultze, "The Generative Mechanisms of Healthcare Digitalization", in Proc. of ICIS 2015.

[27] R. Kohli and S. Johnson, "Digital Transformation in Latecomer Industries: CIO and CEO Leadership Lessons from Encana Oil \& Gas (USA) Inc.”, MISQE, 10(4), 2011, pp. 141-156.

[28] S. Finney and M. Corbett, "ERP Implementation: a Compilation and Analysis of Critical Success Factors", Bus. Pro. Manage. J., 13, 2007, pp. 329-347.

[29] J. J. William and A. Ramaprasad, "A Taxonomy of Critical Success Factors", Eur. J. Inf. Syst. 5(4), 1996, pp 250-260.

[30] I. Alhassan, D. Sammon \& M. Daly, "Data Governance Activities: Analysis of the Literature", J. Dec. Sys. 25(1), 2016, pp. 64-75.

[31] A. L. Strauss \& J. M. Corbin, "Basics of Qualitative Research: Grounded Theory Procedures and Techniques", Thousand Oaks, CA: Sage, 1998.
[32] B. G. Glaser, "Emergence vs Forcing: Basics of Grounded Theory Analysis", Mill Valley, CA, Sociology Press. 1992.

[33] A. M. Hansen, K. Pernille and L. Mathiassen. "Rapid Adaptation in Digital Transformation: A Participatory Process for Engaging IS and Business Leaders," MISQE. 10(4), 2011, pp. 175-185.

[34] M. E. Fonteyn, M. Vettese, D. R. Lancaster and $\mathrm{S}$. BauerWu, "Developing a Codebook to Guide Content Analysis of Expressive Writing Transcripts", Applied Nursing Research, 21(3), 2008, pp. 165-168.

[35] E. Henriette, F. Mondher and B. Imed, "The Shape of Digital Transformation: A Systematic Literature Review", in Proc. of MCIS 2015.

[36] J. Reis, M. Amorim, N. Melão, P. Matos, "Digital Transformation: A Literature Review and Guidelines for Future Research", Trends and Advances in IS Technologies. WorldCIST 2018.

[37] D. Schweer and J. C. Sahl, "The Digital Transformation of Industry - The Benefit for Germany", In: Abolhassan F. (eds) The Drivers of Digital Transformation. Management for Professionals, 2017.

[38] S. J. Berman and A. Marshall, "The Next Digital Transformation: From an IndividualCentered to an Everyone-to-Everyone Economy", Strat. \& Leadership 42(5), 2014, pp. 9-17.

[39] C. Loebbecke and A. Picot, "Reflections on Societal and Business Model Transformation Arising from Digitization and Big Data Analytics: A Research Agenda," J. Strat. Inf. Syst, 24(3), 2015, pp. 149-157.

[40] S. J. Berman, S. J., "Digital Transformation: Opportunities to Create New Business Models", Strategy \& Leadership, 40(2), 2012, pp. 16-24.

[41] L. F. Luna-Reyes and J. R. Gil-Garcia, "Digital Government Transformation and Internet Portals: The CoEvolution of Technology, Organizations and Institutions", GIQ, 31, 2014, pp. 545-555.

[42] C. Matt, T. Hess and A. Benlian, "Digital Transformation Strategies" Bus. Inf. Syst. Eng., 5, 2015, pp. 339-343.

[43] G. Westerman, C. Calméjane, D. Bonnet, P. Ferraris and A. McAfee, "Digital Transformation: A Roadmap for BillionDolllar Organization”, MITSloan Manage. Rev., 2011, pp. 1-68.

[44] G. C. Kane, D. Palmer, A. N. Phillips and D. Kiron, "Is Your Business Ready for a Digital Future?” MITSloan Manage. Rev., 2015. 
[45] P. Weill and S. L. Woerner, "Thriving in an Increasingly Digital Ecosystem," MITSloan Manage. Rev., 2015.

[46] G. C. Kane, D. Palmer, A. N. Phillips and D. Kiron, "Strategy, Not Technology, Drives Digital Transformation: Becoming a Digitally Mature Enterprise”. MITSloan Manage. Rev., 2015.

[47] A. H. Amaye, K. Neville and A. Pope, "Design Drift and Reflective Conversation in Design Science Research: A Case Study of Problem Formulation" 14, in Proc. of ICIS 2017.

[48] G. Vial, "Understanding Digital Transformation: A Review and a Research Agenda," J. of Strat Inf. Syst, 28(2), 2019, pp. 118-144.

[49] T. Hess, C. Matt, A. Benlian, \& F. Wiesböck, "Options for Formulating a Digital Transformation Strategy.” MISQE 15(2), 2016, pp.123-139.

[50] M. H. Ismail, K. Mohamed and Z. Mohamed, "Digital Business Transformation and Strategy: What Do We Know So Far," Cambridge Service Alliance, 2017.

[51] A. Leischnig, S. Wölfl, B. Iven and D. Hein, "From Digital Business Strategy to Market Performance: Insights into Key Concepts and Processes," in proc. of ICIS 2017.

[52] P. G. Krogh, T. Markussen, and A. L. Bang. "Ways of Drifting - Five Methods of Experimentation in Research Through Design." In ICoRD'15-Research into Design Across Boundaries Springer, 1, 2015, pp. 39-50.

[53] A. Yeow, C. Soh and R. Hansen, "Aligning with New Digital Strategy: A Dynamic Capabilities Approach,” J. Strat. Inf. Syst., 27(1), 2018, pp.43-58.

[54] I. Haffke, B. J. Kalgovas and A. Benlian, "The Role of the CIO and the CDO in an Organization's Digital Transformation," in Proc of ICIS 2016.

[55] A. Singh and T. Hess, "How Chief Digital Officers Promote the Digital Transformation of their Companies," MISQE 16(1), 2017, pp. 117.

[56] C. Heavin and D. J. Power, "Challenges for Digital Transformation - Towards a Conceptual Decision Support Guide for Managers," J. of Dec. Syst, 27(1), 2017, pp 38-45.

[57] H. C. Lucas, R. Agarwal, E. K. Clemons, O. A. El Sawy and B. Weber, "Impact Research on Transformational Information Technology: An Opportunity to Inform New Audiences," MISQ, 37(2), 2013, pp. 371-382.
[58] G. C. Kane, D. Palmer, A. N. Phillips and D. Kiron, "Aligning the Organization for its Digital Future,” MITSloan Manage. Rev., 58(1), 2016.

[59] L. Hylving and U. Schultze, "Evolving the Modular Layered Architecture in Digital Innovation: The Case of the Car's Instrument Cluster", 2013.

[60] E. Piccinini, R. W. Gregory and L. M. Kolbe, "Changes in the Producer - Consumer Relationship - Towards Digital Transformation." Changes 3(4), 2015, pp. 16341648.

[61] S. Chanias and T. Hess, "Understanding Digital Transformation Strategy Formation: Insights From Europe's Automotive Industry." in Proc. of PACIS 296. 2016.

[62] J. Schmidt, P. Drews and I. Schirmer, "Digitalization of the Banking Industry: A Multiple Stakeholder Analysis on Strategic Alignment." 2017.

[63] K. Liere-Netheler, K. Vogelsang, S. Packmohr and U. Hoppe, "Towards a Framework for Digital Transformation Success in Manufacturing," in Proceedings of ECIS 2018.

[64] B. Mueller and U. Renken, "Helping Employees to be Digital Transformers - the Olympus. Connect Case" 2017.

[65] K. Liere-Netheler, S. Packmohr, and K. Vogelsang. "Drivers of Digital Transformation in Manufacturing," in Proc. of HICSS 2018.

[66] W. H. DeLone and E. R. McLean, "Information Systems Success: The Quest for the Dependent Variable," Inf. Syst. Res., 3(1), 1992, pp. 60-95.

[67] W. H. Delone and E. R. McLean, "The DeLone and McLean Model of Information Systems Success: Ten Year Update", J. Manage. Inf. Syst., 19(4), 2003, pp. 9 - 30.

[68] G. G. Gable, D. Sedera, and T. Chan, "Reconceptualizing Information System Success: The IS Impact Measurement Model," J. Assoc. for Inf. Syst. (7), 2008, 18.

[69] K. Schwab, "The Fourth Industrial Revolution", Penguin, London, 2017.

[70] K. Högberg, "Organizational Social Media: A Literature Review and Research Agenda," in Proc. of HICSS 2018, pp. 3832-3841.

[71] B. C. Carroll and G. A. Cotter, "A new Generation of Grey Literature: The Impact of Advanced Information Technologies," Publishing Research Quarterly 13(2), 1997, pp. 5-14. 